Provided for non-commercial research and education use. Not for reproduction, distribution or commercial use.

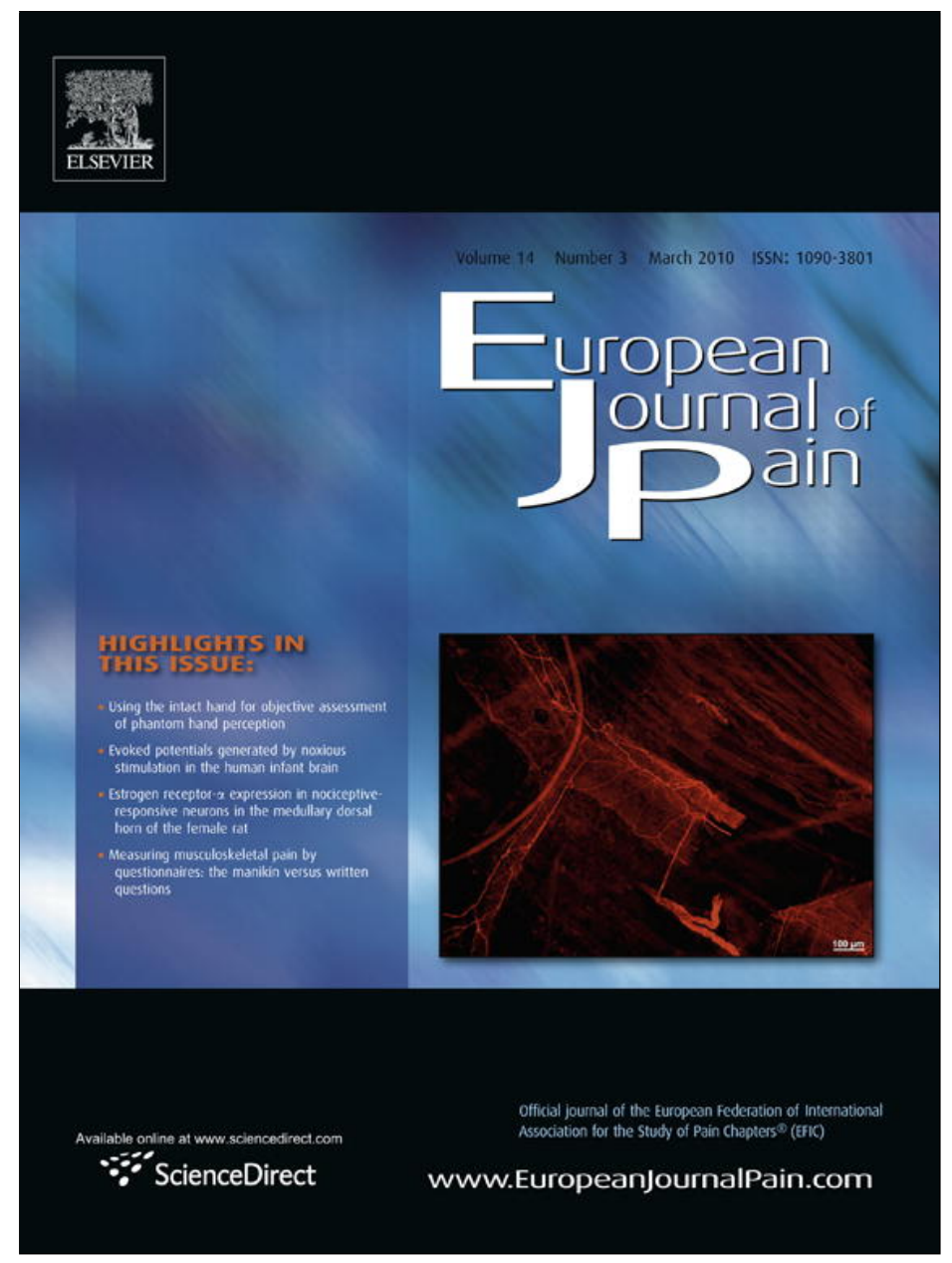

This article appeared in a journal published by Elsevier. The attached copy is furnished to the author for internal non-commercial research and education use, including for instruction at the authors institution and sharing with colleagues.

Other uses, including reproduction and distribution, or selling or licensing copies, or posting to personal, institutional or third party websites are prohibited.

In most cases authors are permitted to post their version of the article (e.g. in Word or Tex form) to their personal website or institutional repository. Authors requiring further information regarding Elsevier's archiving and manuscript policies are encouraged to visit:

http://www.elsevier.com/copyright 


\title{
Differential physiological effects during tonic painful hand immersion tests using hot and ice water
}

\author{
Anouk Streff $^{\mathrm{a}, 1}$, Linn K. Kuehl ${ }^{\mathrm{b}, 1}$, Gilles Michaux ${ }^{\mathrm{a}, *}$, Fernand Anton ${ }^{\mathrm{a}}$ \\ ${ }^{a}$ Laboratory of Psychophysiology, University of Luxembourg, Luxembourg \\ b Institute of Psychobiology, Department of Clinical Physiology, University of Trier, Trier, Germany
}

\section{A R T I C L E I N F O}

\section{Article history:}

Received 13 March 2009

Received in revised form 19 May 2009

Accepted 20 May 2009

Available online 21 June 2009

\section{Keywords:}

Baroreflex hypoalgesia

Cold pressor test

Endogenous pain modulation

Human pain models

Psychophysiology

Psychophysics

\begin{abstract}
A B S T R A C T
The cold pressor test (CPT) is an empirically validated test commonly used in research on stress, pain and cardiovascular reactivity. Surprisingly, the equivalent test with water heated to noxious temperatures (hot water immersion test, HIT) has not been thoroughly investigated. The aim of the present study was to characterize the physiological effects and psychophysics of both tests and to analyze whether the autonomic responses are mainly induced by baroreflexes or a consequence of the pain experience itself. The study consisted of a single session including one CPT $\left(4 \pm 0.2^{\circ} \mathrm{C}\right)$ and one $\mathrm{HIT}\left(47 \pm 0.5^{\circ} \mathrm{C}\right.$; cut-off point $5 \mathrm{~min}$ ) trial performed on 30 healthy drug free volunteers aged 19-57 (median 24) yrs. The sequence of both trials was alternated and participants were randomly assigned to sequence order and parallelized with respect to gender. Physiological parameters (cardiovascular, respiratory and electrodermal activity) and subjective pain intensity were continuously monitored. In addition, pain detection and tolerance thresholds as well as pain unpleasantness were assessed. Both tests were comparable with regard to the time course and intensity of subjective pain. However, a significantly higher increase of blood pressure could be observed during the CPT when compared to the HIT. The HIT appears less confounded with thermoregulatory baroreflex activity and therefore seems to be a more appropriate model for tonic pain.
\end{abstract}

(c) 2009 European Federation of International Association for the Study of Pain Chapters. Published by Elsevier Ltd. All rights reserved.

\section{Introduction}

The cold pressor test (CPT; Hines and Brown, 1936) was originally conceived as a clinical cardiovascular challenge test to identify blood pressure (BP) and heart rate (HR) reactivity after hand immersion into ice water. It also proved to be a reliable experimental model for tonic pain or pain tolerance assessment (Mitchell et al., 2004). It has been hypothesized that the relationship between cardiovascular excitability and pain induction is primarily due to the extensive rise in BP caused by the thermoregulatory vasoconstriction of blood vessels in deep tissue (Wolf and Hardy, 1941).

Hand immersion in painful cold or hot water has also been used for experimental characterization of endogenous pain modulation, especially as a trigger stimulus for diffuse noxious inhibitory controls (DNIC). The DNIC phenomenon relates to the inhibition of nociceptive dorsal horn activity and pain sensations induced by

\footnotetext{
* Corresponding author. Address: University of Luxembourg, Campus Limpertsberg BR 3.03A, Avenue de la Faïencerie 162a, Luxembourg. Tel.: +352 466644 6652; fax: +3524666446282 .

E-mail address: gilles.michaux@uni.lu (G. Michaux).

${ }^{1}$ Both authors equally contributed to this study.
}

additional heterotopic noxious stimulation, and has been postulated to serve as a contrast-sharpening filter process (Le Bars et al., 1979a,b, 1992). Animal studies have shown that it is mediated via an extra-segmental inhibitory process involving the medullary subnucleus reticularis dorsalis (Villanueva et al., 1996) and a reticular involvement may also be assumed in humans (cf. Le Bars et al., 1992).

The validity of cold-water immersion as a heterotopic noxious counter-stimulus for DNIC induction may however be hampered by confounding interactions of cardiovascular and pain regulatory systems. Experimentally induced, as well as constitutional hypertension is associated with reduced pain sensitivity, a phenomenon commonly referred to as baroreflex hypoalgesia (for overview see Bruehl and Chung, 2004; Randich and Maixner, 1984; Ring et al., 2008). Observed cold-pressor related reductions in pain ratings may thus not selectively be attributable to DNIC, baroreflex mechanisms induced by thermoregulatory vasoconstriction may be involved as well. Painful hot and cold water stimulations are comparable with regard to their inhibitory effects on subjective pain experience (Granot et al., 2008). The two stimulation paradigms are thus interchangeably used, although little is known about possible physiological specificities and underlying mechanisms. 
In the present study we contrasted the hot and ice water immersion tests with regard to their psychophysical and physiological (cardiovascular, respiratory and electrodermal activity [EDA]) characteristics. Our main goal was to validate the relative usefulness of the two paradigms for studies investigating DNIC effects.

\section{Methods}

\subsection{Subjects}

$N=35$ healthy (18 female and 17 male; two left-handed) volunteers aged between 19 and 57 years (median [Md] age 24 yr.) participated in the study. The subjects were recruited at the University of Luxembourg and received monetary compensation for their participation. All participants gave informed written consent, were drug free (no drug or alcohol intake $>24 \mathrm{~h}$ before the study, except oral contraceptives) and did not suffer from any medical, neurological, psychiatric or psychological disorder nor did they manifest any substance (incl. nicotine) abuse.

The study consisted of a single session (duration: $75 \mathrm{~min}$ ) including one hot water immersion trial (HIT) and one cold pressor trial (CPT). The sequence of both trials was alternated (AB-BA scheme) and participants were randomly assigned to sequence order and parallelized with respect to gender. The experimental protocol was in accordance with the ethical guidelines of IASP (Charlton, 1995) and met the criteria for an exemption from local ethical committee approval.

\subsection{Algesimetry}

Tonic thermal pain was induced by immersing the right hand up to the wrist in a $12 \mathrm{~L}$ tank with circulating hot $\left(47-48^{\circ} \mathrm{C}\right)$ or cold $\left(3-4^{\circ} \mathrm{C}\right)$ water. A cut-off point of 5 min was predefined, which guaranteed a time interval sufficient for reliable psychophysiological recordings of cardiovascular parameters (Sollers JJ, personal communication, 03/09/2008). The temperature of the hot water bath was held constant with a commercially available submergible heater and a digital controller, whereas an external chiller was used for the cold water bath (Aqua Medic GmbH, Germany). External aquarium pumps ensured water circulation in both water containers.

Subjective pain intensity was numerically rated on a verbally anchored scale ( 0 corresponding to no pain and 100 to the maximal imaginable pain) every $15 \mathrm{~s}$ during both pain tests. Pain unpleasantness was quantified using a $10-\mathrm{cm}$ visual analogue scale (VAS; verbal anchors: not at all unpleasant and extremely unpleasant) immediately after each test. Apprehension (nervous tension) associated with the pain test was determined using a 5-point Likert scale ( 1 = minimal tension; 5 = maximal tension $)$. Furthermore, qualitative (i.e. affective and sensory) aspects of the pain experience during cold/hot water immersion were assessed with an adjective scale (Schmerzempfindungs-Skala, SES [pain sensation scale]; Geissner, 1996).

In addition, detection thresholds for cold and warm sensation (method of limits) as well as cold and heat pain (staircase-method) were evaluated, employing a $30 \times 30 \mathrm{~mm}$ contact thermode attached to the volar surface of the left forearm (TSA-II NeuroSensory Analyzer; Medoc Advanced Medical Systems Ltd., Israel).

\subsection{Psychophysiological recording}

$\mathrm{BP}$ was continuously monitored on the wrist of the left arm with a noninvasive BP amplifier (NIBP100A; BIOPAC Systems, Inc., USA). Cardiac activity was assessed with a pre-cordial lead II electrocardiograph (ECG100C; BIOPAC Systems, Inc., USA; with $0.5-\mathrm{Hz}$ high pass and $35 \mathrm{~Hz}$ low pass filtering) employing disposable pre-gelled $\mathrm{Ag}-\mathrm{AgCl}$ electrodes. Subjects were grounded through a surface electrode attached to the chest. Respiration rate (RR) was obtained (with $0.05-\mathrm{Hz}$ high pass and $1-\mathrm{Hz}$ low pass filtering) using strain gauge belts positioned on the thorax and the abdomen (TSD201; BIOPAC Systems, Inc., USA). EDA was recorded with two 6-mm diameter domed $\mathrm{Ag}-\mathrm{AgCl}$ electrodes (SS3LA; BIOPAC Systems, Inc., USA) and processed through a constant voltage $(0.5 \mathrm{~V})$ coupler (GSR100C; BIOPAC Systems, Inc., USA; with $5 \mu \mathrm{S} / \mathrm{V}$ signal gain and $1-\mathrm{Hz}$ low pass filtering). Transducers were filled with isotonic electrode paste (formulated with $0.5 \%$ saline in a neutral base) and fixed on the mid-phalanx of the third and the fourth finger of the left hand. The skin temperature of both hands was measured on the palms by using a digital infrared thermometer (Sanowell Scaneo; Hofmann GmbH, Germany). The laboratory room was mechanically ventilated with ambient temperature maintained at $23.5 \pm 0.5^{\circ} \mathrm{C}$. The AcqKnowledge software package (BIOPAC Systems, Inc., USA) was used for the collection and analysis (online and offline transformations) of the psychophysiological data.

\subsection{Psychometrics}

To test whether inter-individual differences in behavioral inhibition or activation systems might influence reactivity in the CPT and HIT, subjects were asked to fill out the BIS/BAS-scales (Carver and White, 1994).

\subsection{Procedure}

Each session began with the installation of the subject in upright position onto the experimental chair (approximately $90^{\circ}$ inclination) and electrode/transducer placement. This was followed by a 5-min adaptation period and the measurement of detection thresholds for thermal sensation and pain (see experimental protocol in Fig. 1).

Subsequently, the registration of physiological parameters was started with the recording of a 5-min resting baseline (BL1), succeeded by the first water test (CPT or HIT, depending on the individual sequence). The subjects were instructed to immerse their right hand up to the wrist in the corresponding water tank and to verbally indicate the time point of the first pain sensation (i.e. pain threshold). Further, they were instructed to rate their pain sensation every $15 \mathrm{~s}$ on a numerical rating scale (NRS). The subjects were asked to leave their hand in the water container until the pain tolerance level was reached. The alternate water immersion test (CPT or HIT, respectively) followed after a 10-min rest period serving for BL assessment (BL2). For adaptation of skin temperature, the test hand was immersed in a container with tepid water $\left(32^{\circ} \mathrm{C}\right.$ ) during the first $3 \mathrm{~min}$ of this pause. Skin temperature on both hands was measured before and after each BL and test recording. Only the last two minutes of the corresponding BLs (BL1 and 2, respectively) were used for standardization of physiological data.

\subsection{Data reduction and analysis}

Due to technical problems during psychophysiological recording, the data of three subjects were incomplete and thus not included in analysis. Furthermore, two participants felt no pain sensations during one or both water tests and had to be excluded as well, leaving a statistical population of $N=30$.

The mean systolic BP and HR were calculated separately for both test periods and relativized to mean BL (1-min recording 2 min before the beginning of CPT and HIT, respectively) values. The mean RR was computed for thoracic and abdominal respiration 


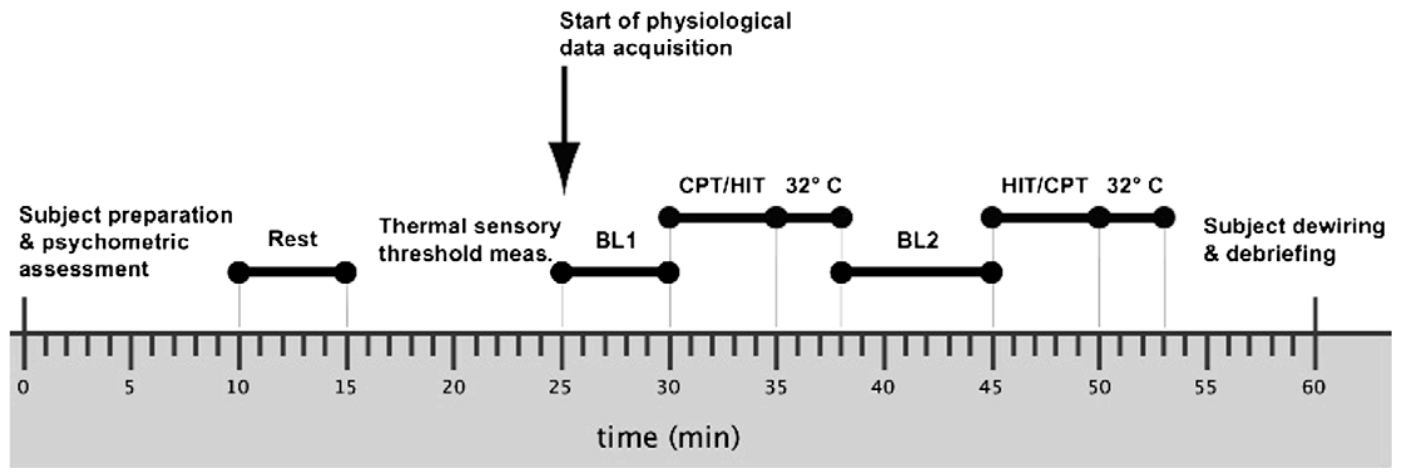

Fig. 1. Experimental protocol: cold pressor test (CPT), and hot water immersion test (HIT).

separately (re-sampling rate $=50 \mathrm{~Hz}$ ). The standard deviation of nonspecific EDA amplitudes for the first test minute was calculated offline and served as tonic EDA parameter (cf. Besthorn et al., 1989). The 1-min recording preceding test onset served as BL for RR and EDA. Overall pain experience during the immersion tests was computed as the geometrical grand mean of all subject's ratings different from zero.

All statistical analyses were conducted using the Statistical Package for Social Sciences (SPSS Inc., USA). Graphs were created with SigmaPlot (Systat Software Inc., USA) and Temporis (Bartas Technologies LLC, USA). Effect size computations were carried out with the $\mathrm{G} *$ Power program (Faul et al., 2007). Parametric ( $t$ tests for paired samples; Pearson product-moment correlation coefficient $[r])$, non-parametric tests and correlation coefficients (Wilcoxon's signed rank test; Spearman's rho $\left[r_{s}\right]$ ) were computed as appropriate (e.g. non-parametric tests in the case of skewed data distributions). For normally distributed data, the arithmetic mean and standard error of the mean $(A M \pm S E M)$ were used as measures of central tendency and variability, whereas asymmetrically distributed data are represented as median plus mean absolute deviation $(M A D)$ or range. As in the analysis of psychometric data we tested for the null hypothesis (that there is no difference between both tests), a more conservative two-tailed significance level of $\alpha=.20$ was chosen. For the analysis of psychophysiological data, a one-tailed $p$-value of less than .05 was considered significant.

\section{Results}

\subsection{Psychophysical and psychometric data}

Pain thresholds (i.e. latency to detection of first pain) correlated moderately between both tests $\left(r_{\mathrm{s}}=.33, p<.05\right)$ and were significantly higher for the CPT than for the HIT $\left(z_{29,1}=2.9, p=.003\right.$, effect size $[d]=.52$ ), although the absolute time difference of $3 \mathrm{~s}$ (CPT: $M d=13 \mathrm{~s}$, range $=5-30 \mathrm{~s}$; HIT: $M d=10 \mathrm{~s}$, range $=1-28 \mathrm{~s}$ ) may be considered negligible (see Fig. 2 and Table 1). Pain tolerance levels (CPT: $M d=300 \mathrm{~s}$, range $=63-300 \mathrm{~s}$; HIT: $M d=150 \mathrm{~s}$, range $=35-$ $300 \mathrm{~s})$ were also higher during cold-water immersion $\left(z_{29,1}=-1.91, p=.06\right)$ and highly correlated between both tests $\left(r_{\mathrm{s}}=.48, p<.01\right)$. As expected, both immersion tests were comparable with regard to the time course of subjective pain experience (see Fig. 2a, and c) and pain increase (see Fig. 2; 63 compared to 67 NRS-units for CPT and HIT, respectively; $t_{29,1}=-1.22, p=.22$ and $\left.r_{\mathrm{s}}=.41, p<.05\right)$. However, when analyzing relative summation of pain as percent difference between the first and last pain rating, a significant difference could be shown between both tests $\left(\Delta \%=30-56 \%\right.$ for CPT and HIT, $z_{29,1}=-2.57, p=.01$; cf. (Fig. $2 \mathrm{e}$ ). No sequence effects were found with respect to subjective pain intensity (sequence CPT-HIT: $A M \pm S E M=62 \pm 4.7$ and $67 \pm 5.5$ for
CPT and HIT, respectively; $t_{29,1}=-.72, p=.49$; sequence HIT-CPT: $A M \pm S E M=63 \pm 6.1$ and $66 \pm 5.5$ for HIT and CPT, respectively; $t_{29,1}=-.50, p=.63$ ). Nonetheless, pain thresholds were negatively correlated with the percent increases in pain for both tests $\left(r_{\mathrm{s}}=-.40, p<.05\right.$ for CPT and $r_{\mathrm{s}}=-.54, p<.01$ for HIT). Interestingly, pain thresholds did not correlate with the pain tolerance levels, but with overall subjective pain intensity (see Fig. 2d), although this relationship became significant for the CPT only $\left(r_{\mathrm{s}}=.63, p<.01\right)$.

Both tests were perceived as highly unpleasant and were evaluated similarly with regard to the affective and sensory dimensions of the pain experience (cf. Fig. 2b). Unpleasantness correlated with overall subjective pain intensity in both tests $\left(r_{\mathrm{s}}=.43, p<.05\right.$ for the CPT and $r_{\mathrm{s}}=.55, p<.01$ for the HIT) as well as with pain tolerance $\left(r_{s}=-.40, p<.05\right)$, which again was only true for the CPT. On the other hand, significant correlations between unpleasantness $\left(r_{\mathrm{s}}=.38, p<.05\right)$, subjective pain intensity $\left(r_{\mathrm{s}}=.43, p<.05\right)$, pain tolerance level $\left(r_{\mathrm{s}}=-.40, p<.05\right)$ and the affective SES scale could only be observed during hot water immersion, but not for the CPT. These observations may constitute a first indication of a more discernable pain sensation induced by the HIT. There were no consistent relations between the quantitative sensory parameters and inter-individual differences in behavioral inhibition or activation (i.e. on the BIS/BAS scales) with the exception of a positive correlation between unpleasantness and behavior inhibition during CPT (total BIS score; $r=.48, p<.01$ ). Thus a more intense pain experience may be associated with a stronger avoidance behavior, which is further supported by the fact that the total BIS score showed a negative correlation with pain tolerance $(r=-.40, p<.05)$.

\subsection{Psychophysiological data}

Significantly different overall (aggregated over test time) BP levels were observed during both tests (absolute values of 159$152 \mathrm{mmHg}$ for CPT and HIT, respectively; $t_{29,1}=2.81, p=.009$ ). More to the point, the CPT produced a stronger rise in BP $(\Delta \%=16 \%)$ than the HIT $\left(\Delta \%=8 \% ; t_{29,1}=0.85, p=.0002\right)$, calculated as percent differences relative to $\mathrm{BL}$ (see Fig. 3 and Table 2).

Both tests also differed with respect to HR variability (ratio between low and high frequency components [LF/HF ratio] of the HR variability spectra relative to BL: 2.5 for CPT and 1.5 for HIT; $\left.t_{29,1}=2.49, p=.019\right)$ and with respect to the first test minute of EDA (or skin conductance level: $0.14-0.22 \mathrm{mS}$ for CPT and HIT, $\left.t_{29,1}=-1.81, p=.003\right)$.

HR on the other hand was highly correlated $(r=.80, p<.01)$ during both tests and consequently did not differ significantly (80-81 $\mathrm{BPM}$ for CPT and HIT, $t_{29,1}=-.97, p=.17$ ). HRs recorded during BL were however significantly different from the ones recorded 

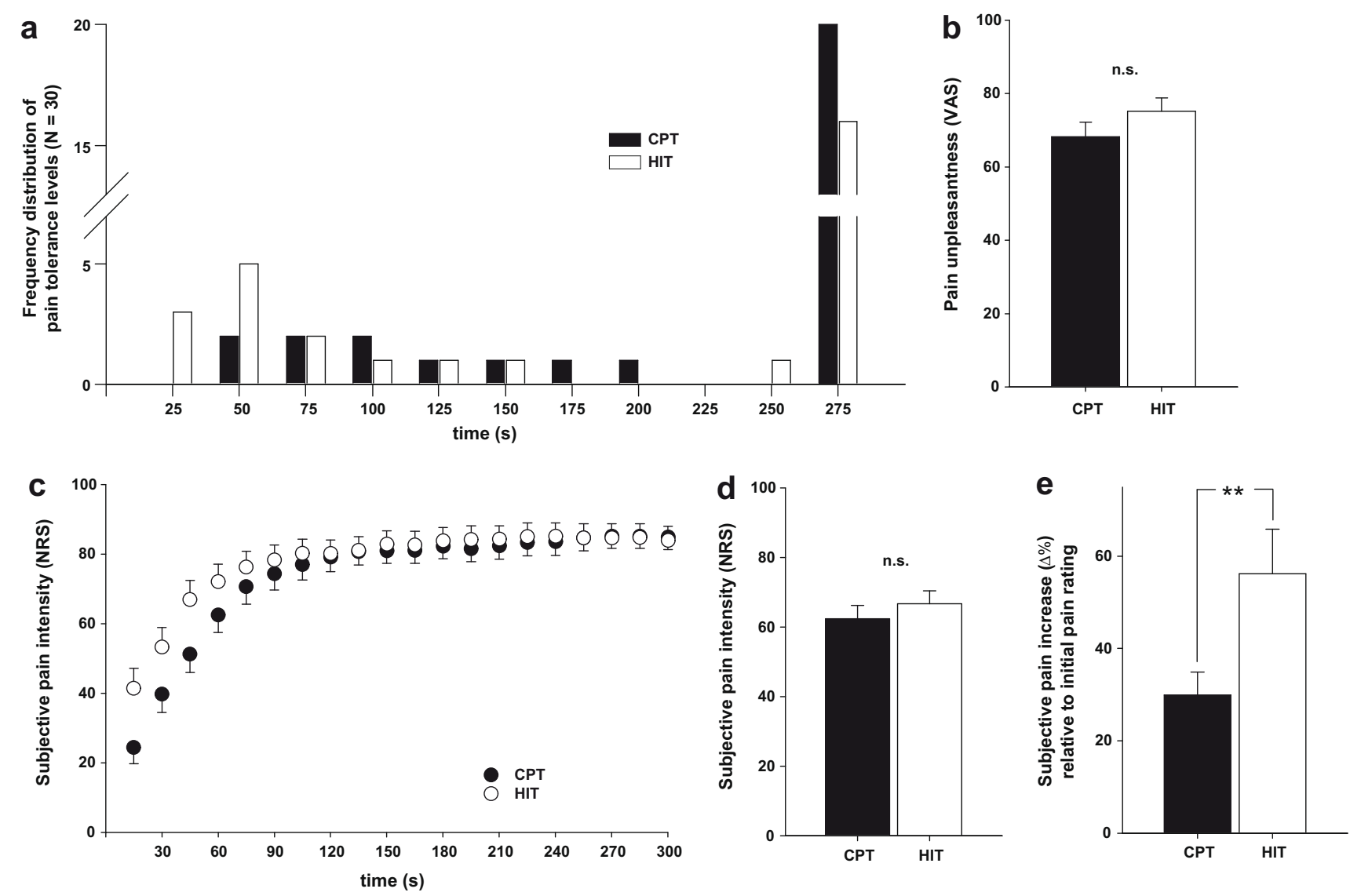

Fig. 2. Psychophysical data. (a) Frequency distribution of pain tolerance levels $(N=30)$ for both immersion tests. (b) Overall pain unpleasantness. (c) Time course of subjective pain intensity. (d) Overall subjective pain intensity (individual geometric means aggregated over test duration). (e) Temporal summation of subjective pain intensity (percent increase relative to initial pain rating). All data expressed as $A M \pm S E M .{ }^{* *} p<.01$.

Table 1

Psychophysical data.

\begin{tabular}{|c|c|c|c|c|c|c|c|}
\hline & \multicolumn{2}{|l|}{ CPT } & \multicolumn{5}{|l|}{ HIT } \\
\hline & $\begin{array}{l}\text { Measures of central } \\
\text { tendency + dispersion }\end{array}$ & Range & $\begin{array}{l}\text { Measures of central } \\
\text { tendency + dispersion }\end{array}$ & Range & $\begin{array}{l}\text { Correlation } \\
\text { CPT/HIT }\end{array}$ & $\begin{array}{l}\text { Test value } \\
(\mathrm{df}=29)\end{array}$ & $\begin{array}{l}p \text {-value } \\
\text { (2-tailed) }\end{array}$ \\
\hline Pain threshold (s) & $13 \pm 6^{a}$ & $5-30$ & $10 \pm 6$ & $1-28$ & $r_{\mathrm{s}}=.33^{*}$ & $-2.93^{\mathrm{b}}$ & $.003^{* *}$ \\
\hline Pain tolerance level (s) & $300 \pm 93$ & $63-300$ & $150 \pm 124$ & $35-300$ & $r_{\mathrm{s}}=.48^{* *}$ & -1.91 & .06 \\
\hline $\begin{array}{l}\text { Overall subjective pain intensity } \\
\text { (aggregated over time) }\end{array}$ & $63 \pm 4^{c}$ & $30-93$ & $67 \pm 4$ & $22-96$ & $r=.41^{*}$ & $-1.22^{\mathrm{d}}$ & .22 \\
\hline $\begin{array}{l}\text { Subjective pain increase }(\% \Delta) \text { relative } \\
\text { to initial rating }\end{array}$ & $30 \pm 5$ & $1-88$ & $56 \pm 10$ & $0-250$ & $r=.34$ & -2.57 & $.01^{* *}$ \\
\hline Unpleasantness (VAS) & $68 \pm 4$ & $18-100$ & $75 \pm 4$ & $28-100$ & $r=-.18$ & -1.19 & .24 \\
\hline Affectivity (SES) & $39^{e}$ & $34-59$ & 40 & $33-62$ & $r=.34$ & -.32 & .75 \\
\hline
\end{tabular}

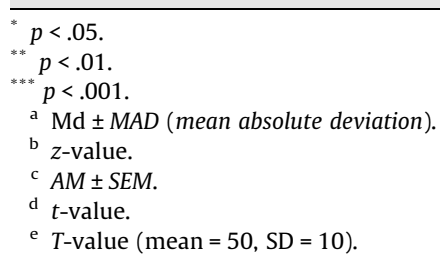

during test periods (76 to $80 \mathrm{BPM}$ for BL and CPT, $t_{29,1}=-2.31$, $p=.01$; and 76-81 BPM for BL and HIT, $t_{29,1}=-4.92, p=.00002$ ). A significantly different HR between $\mathrm{BL}$ and test time was a result that could only be replicated for the HIT (76-81 BPM for BL and HIT, $t_{29,1}=2.10, p=.04$ ) when the initial 15-s phase was taken into consideration. The subjective pain intensity and the increase of the HR during this initial phase correlated $\left(r_{s}=.46, p<.05\right)$.
The calculated percent difference in BP correlated with the EDA $(r=.43, p<.05)$ and with the mean HR $(r=.44, p<.05)$. This was again the case only for the HIT.

As to RR, no difference was found in thoracic (197-191 beats per test [BPT] for CPT and HIT, respectively; $t_{29,1}=.77, p=.22$; $r=.47, p<.05)$ nor in abdominal respiration $(184-188$ BPT for CPT and HIT, respectively; $\left.t_{29,1}=-.57, p=.29, r=.45 ; p<.05\right)$ over 

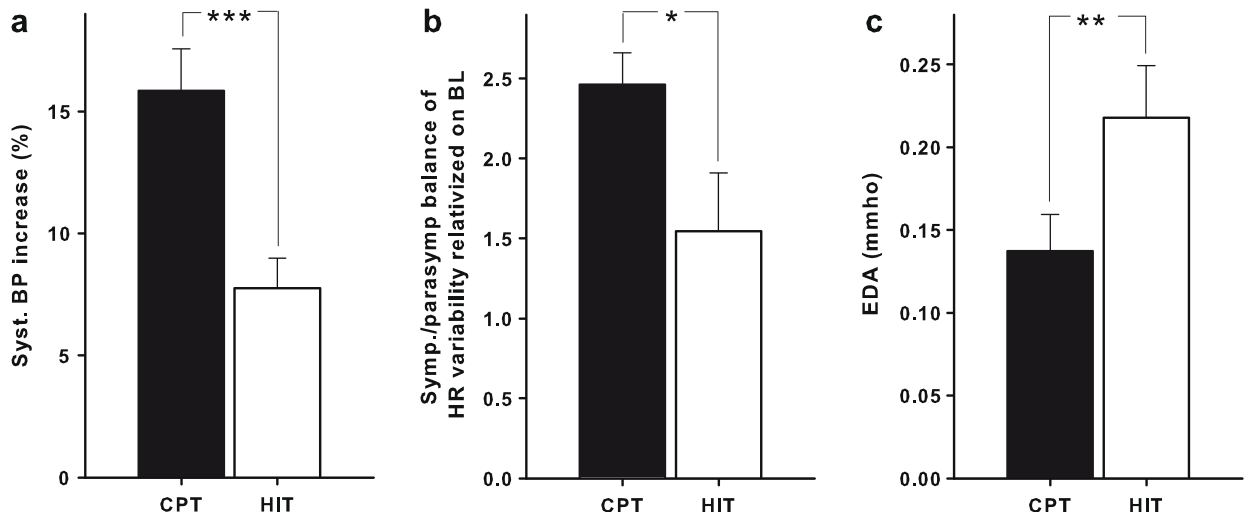

Fig. 3. Psychophysiological data. (a) Percent blood pressure increase relative to baseline (BL). (b) Sympathetic/parasympathetic balance rel. to BL. (c) Spontaneous electrodermal fluctuations rel. to BL. All data expressed as $A M \pm S E M .{ }^{* * *} p<.001,{ }^{* *} p<.01, " p<.05$.

Table 2

Psychophysiological data

\begin{tabular}{|c|c|c|c|c|c|c|c|c|}
\hline & \multicolumn{2}{|l|}{ CPT } & \multicolumn{2}{|l|}{ HIT } & \multirow{2}{*}{$\begin{array}{l}\text { Correlation } \\
\text { CPT/HIT }\end{array}$} & \multirow{2}{*}{$\begin{array}{l}t \text {-value } \\
(d f=29)\end{array}$} & \multirow{2}{*}{$\begin{array}{l}p \text {-value } \\
\text { (2-tailed) }\end{array}$} & \multirow{2}{*}{$\begin{array}{l}\text { Effect size } \\
(d)\end{array}$} \\
\hline & Mean \pm SEM & Range & Mean $\pm S E M$ & Range & & & & \\
\hline Syst. blood pressure $(\mathrm{mmHg})$ & $159 \pm 4$ & $118-211$ & $152 \pm 4$ & $113-196$ & $r=.74^{* * *}$ & 2.81 & $.009^{* * *}$ & .46 \\
\hline Increase of syst. blood pressure $(\% \Delta)$ & $16 \pm 2$ & $4-48$ & $8 \pm 1$ & $7-21$ & $r=.11$ & 4.00 & $.0004^{* * *}$ & .72 \\
\hline $\begin{array}{l}\text { Heart rate variability (symp./parasymp.balance } \\
\text { relative to } \mathrm{BL} \text { ) }\end{array}$ & $2.5 \pm 0.2$ & $0.2-4$ & $1.5 \pm 0.4$ & $-6-4$ & $r=.25$ & 2.49 & $.019^{*}$ & .52 \\
\hline Heart rate $(\mathrm{BPM})$ & $80 \pm 2$ & $65-104$ & $81 \pm 2$ & $64-114$ & $r=.80^{* * *}$ & -.97 & .17 & - \\
\hline Thoracic respiration rate (BPT) & $197 \pm 8$ & $131-342$ & $191 \pm 7$ & $119-284$ & $r=.47^{*}$ & 0.77 & .22 & - \\
\hline Abdom. respiration rate (BPT) & $184 \pm 7$ & $109-298$ & $188 \pm 8$ & $101-333$ & $r=.45^{*}$ & -0.57 & .29 & - \\
\hline $\mathrm{EDA}(\mathrm{mS})$ & $0.14 \pm 0.02$ & $0.004-0.45$ & $0.22 \pm 0.03$ & $0.003-0.6$ & $r=.62^{* * *}$ & -1.81 & $.003^{* *}$ & .53 \\
\hline
\end{tabular}

$p<.05$.

*** $p<.01$.

$p<.001$.

the entire test duration. Additionally, no differences relative to $\mathrm{BL}$ (thoracic RR: $188-189$ BPT for BL and CPT, $t_{29,1}=0.04, p=.9 ; 191-$ 183 BPT for BL and HIT, $t_{29,1}=-0.88, p=.4$; abdominal RR: 183 177 BPT for BL and CPT, $t_{29,1}=-0.94, p=.4 ; 184-179$ BPT for BL and HIT, $t_{29,1}=-0.52, p=.6$ ) could be observed. A high correlation between thoracic and abdominal RR was only identified for the CPT $(r=.59, p<.01)$. During the CPT, but not during the HIT, the respiration parameters correlated with the mean $\mathrm{HR}$ (thoracic $\mathrm{RR} \times \mathrm{HR}$ : $r=.58, p<.01$; abdominal RR $\times$ HR: $r=.38, p<.05)$.

\section{Discussion}

The major goal of the present more methodologically oriented study was to investigate the internal validity of noxious water immersion as a tonic pain stimulus for DNIC induction. Internal validity refers to the validity of causal inferences (cf. Campbell and Stanley, 1963) and here to the degree to which a test non-spuriously induces the target phenomenon it purports to elicit (i.e. that its effects on the dependent variables under study are not confounded with another moderating factor and thus may only be attributed to the hypothesized underlying phenomenon). Since the cardiovascular regulations induced by local cooling of the extremities may themselves engender a reduced pain sensitivity in the sense of a baroreflex hypoalgesia (Duschek et al., 2007), using noxious cold as a DNIC trigger could result in reactive testing by producing extra-segmental pain reduction through the thermal and not the nociceptive qualities of the stimulus. Accordingly, it has already been postulated that pain processing and modulation may be highly intermingled with cardiovascular changes induced during the CPT (see Peckerman et al., 1991 for overview). More to the point, local cooling of the finger has been shown to cause a prominent pain-associated vasoconstriction for several minutes (Kreh et al., 1984).

By contrasting cold to hot water immersion and analyzing the concurrent physiological arousal, especially cardiovascular reactivity, we wanted to investigate whether the HIT would be a less sympathetically confounded tonic pain model. We did not explicitly test for the capacity of both tests to induce pain inhibition, since both tests are analogous in this regard as Granot et al. (2008) documented.

We observed that both immersion tests were quite comparable with respect to temporal summation, unpleasantness and subjective intensity of pain. With the stimulation temperatures chosen in this study-on the order of those commonly used in DNIC investigations (cf. Granot et al., 2008; Lautenbacher et al., 2008), the HIT produced, however, a slightly higher subjective pain experience and was tolerated for a shorter period of time.

Both tests produced pronounced EDA fluctuations and tachycardia during the beginning of the immersion, an increase that returned to baseline levels within the second minute of the test. Spontaneous fluctuations of EDA were higher during the HIT, but contrary to Dowling (1983), who found a positive correlation between skin conductance level and pain tolerance, we could not identify any relationship between respiratory, electrodermal and algesimetric parameters. Correlations between mean thoracic and abdominal RR and HR were only found for the CPT (Steptoe et al., 1984; see also Weise et al., 1993), which could be the result of a potential respiratory sinus arrhythmia. This finding further supports a relatively higher baroreflex activity during coldwater immersion. The results of the HR variability parameter 
substantiate this conclusion as well, since we observed a higher sympathetic activity during the CPT than during the HIT.

With regard to HR, we found enhanced values compared to $\mathrm{BL}$ in both tests, which is largely documented for the CPT and congruent with data from Kondo et al. (2001), who observed an overall increased HR during lower leg immersion even in innocuous $42{ }^{\circ} \mathrm{C}$ water. Interestingly, the forehead CPT has even been shown to cause HR decreases (Peckerman et al., 1991), which could be explained by a reduced sympathetic innervation of the forehead.

Both immersion tests lead to increases in BP, which is also in line with data from former investigations (see Lovallo, 1975 and Lovallo et al., 1985 for review on CPT and Tousignant-Laflamme et al., 2005 for HIT). The less pronounced cardiovascular effects during the HIT compared to the CPT are compatible with the observed inverse relationship between water temperature range $\left(0-28{ }^{\circ} \mathrm{C}\right)$ and size of HR rise (Kregel et al., 1992). Despite the observed increases in both tests and a more pronounced pain experience during the HIT, the cardiovascular changes were more prominent during the CPT with a higher increase of BP and a lower LF/HF ratio (i.e. sympathetic-parasympathetic balance).

The postulation that physiological changes induced by hot water are due to a genuine nocifensive rather than a thermoregulatory reaction was further corroborated by the positive correlation between pain tolerance and BP increase in the HIT trial, but the lack of such a correlation during the CPT. A positive, albeit gender-specific relationship between $\mathrm{HR}$ and pain experience was also found by Tousignant-Laflamme and colleagues (2005) in an investigation using only the HIT. The absence of a correlative relationship between pain ratings during CPT and HR on the other hand, were in line with findings by other investigators (Peckerman et al., 1991). Interestingly, Dowling (1983) found a negative correlation between HR level and pain tolerance level during the resting and anticipation period before a CPT. This correlation became insignificant $40 \mathrm{~s}$ after the immersion, i.e. when pain had started to develop. This divergence between indicators of pain perception and cardiovascular reactivity observed in the two immersion tests is likely to be related to a lower sympathetic or thermoregulatory involvement during the HIT (Appenzeller, 2000).

Trying to differentiate between DNIC and baroreflex hypoalgesia using pharmacological manipulations has proven to be complicated. Although it has been demonstrated that opiates may reduce increases in subjective pain and BP induced by CPT, the causality and moderation of this effect remains elusive, due to the additional vasodilatory effectiveness of these substances (Posner et al., 1985; see also Edwards et al., 2004). The analgesic ibuprofen has, on the other hand, failed to reduce pain during CPT despite of its vasodilatory effects. The fact that pain was even increased in this study could speculatively be attributed to an inhibition of baroreflex hypoalgesia (Peckerman et al., 1991).

In summary, our data indicate that the HIT is less confounded with thermoregulatory baroreflex activity and therefore a more appropriate model to produce experimental tonic pain with less autonomic arousal. Nonetheless, the HIT might also provoke significant increases in BP, so that the induction of baroreflex hypoalgesia may not be excluded for this model. Due to the complex interactions between baroreflex, opioid and descending pain modulation mechanisms (see France, 1999 for review and discussion), it is difficult to experimentally differentiate between baroreflex and multi-segmental DNIC-induced hypoalgesia in humans. Although pain models employing water immersion as well as the ischemic tourniquet pain test (Smith et al., 1966) are able to induce hypoalgesia, they are massively confounded with cardiovascular regulations that may be majorly responsible for this effect (cf. Pertovaara et al., 1984). Thus, the pain modulation provoked by these two models should strictly speaking be described as an unspecified form of descending inhibition rather than a perceptual correlate of
DNIC. Further research with other tonic pain models, using psychophysics combined to psychophysiology, is needed to characterize tonic pain models that are less likely to induce interfering vegetative reactions, and therefore more appropriate for induction of distinct forms of descending pain control.

\section{Acknowledgements}

This study was supported by grants from the University of Luxembourg (R1F303C07; AS), the Luxembourg Ministry of Culture, Higher Education and Research (BFR07-102) and the International Research Training Group "Psychoneuroendocrinology of Stress: From Molecules and Genes to Affect and Cognition" of the German Research Foundation (GRK 1389/1; LK). The authors declare that there are no conflicts of interest. The assistance of Julia Rihm with data input is gratefully acknowledged.

\section{References}

Appenzeller O. The autonomic nervous system. Part II. Dysfunctions. In: Vinken PJ, Bruyn GW, editors. Handbook of Clinical Neurology 2000;Vol. 75. Amsterdam: Elsevier; 2000. p. 1-52.

Besthorn C, Schellberg D, Pfleger W, Gasser T. Using variance as a tonic SCR parameter. J Psychophysiol 1989;3:419-24.

Bruehl S, Chung OY. Interactions between the cardiovascular and pain regulatory systems: an updated review of mechanisms and possible alterations in chronic pain. Neurosci Biobehav Rev 2004;28:395-414.

Campbell DT, Stanley JC. Experimental and quasi-experimental designs for research. Chicago: Rand McNally; 1963.

Carver CS, White TL. Behavioral inhibition, behavioral activation, and affective responses to impending reward and punishment: the BIS/BAS scales. J Pers Soc Psychol 1994;67:319-33.

Charlton E. Ethical guidelines for pain research in humans. Pain 1995;63:277-8.

Dowling J. Autonomic measures and behavioral indices of pain sensitivity. Pain 1983; $16: 193-200$

Duschek S, Mück I, Reyes del Paso GA. Relationship between baroreceptor and cardiac reflex sensitivity and pain experience in normotensive individuals. Int J Psychophysiol 2007;65:193-200.

Edwards RR, Ness TJ, Fillingim RB. Endogenous opioids, blood pressure, and diffuse noxious inhibitory controls: a preliminary study. Percept Motor Skills 2004;99:679-87.

Faul F, Erdfelder E, Lang AG, Buchner A. G*Power 3: a flexible statistical power analysis for the social, behavioral, and biomedical sciences. Behav Res Methods 2007;39:175-91.

France C. Decreased pain perception and risk for hypertension: considering a common physiological mechanism. Psychophysiology 1999;36:683-92.

Geissner E. Die Schmerzempfindungs-Skala [Pain Sensation Scale]. Göttingen: Hogrefe; 1996.

Granot M, Weissman-Fogel I, Crispel Y, Pud D, Granovsky Y, Sprecher E, et al. Determinants of endogenous analgesia magnitude in a diffuse noxious inhibitory control mechanism (DNIC): do conditioning stimulus painfulness, gender and personality variables matter? Pain 2008;136:142-9.

Hines EA, Brown GE. The cold pressor test for measuring the reactibility of the blood pressure: data concerning 571 normal and hypertensive subjects. Am Heart J 1936;11:1-9.

Kondo N, Shibasaki M, Aoki K, Koga S, Inoue Y, Crandall CG. Function of human eccrine sweat glands during dynamic exercise and passive heat stress. J Appl Physiol 2001;90:1877-81.

Kregel KC, Seals DR, Callister R. Sympathetic nervous system activity during skin cooling in humans: relationship to stimulus intensity and pain sensation. J Physiol 1992;454:359-71.

Kreh A, Anton F, Gilly H, Handwerker HO. Vascular reactions correlated with pain due to cold. Exp Neurol 1984;85:533-46.

Lautenbacher S, Kunz M, Burkhardt S. The effects of DNIC-type inhibition on temporal summation compared to single pulse processing: does sex matter? Pain 2008;140:429-35.

Le Bars D, Dickenson AH, Besson JM. Diffuse noxious inhibitory controls (DNIC) I. Effects on dorsal horn convergent neurones in the rat. Pain 1979a;6: 283-304.

Le Bars D, Dickenson AH, Besson JM. Diffuse noxious inhibitory controls (DNIC) II. Lack of effect on non-convergent neurones, supraspinal involvement and theoretical implications. Pain 1979b;6:305-27.

Le Bars D, Villanueva L, Bouhassira D, Willer JC. Diffuse noxious inhibitory controls (DNIC) in animals and in man. Patol Fiziol Eksp Ter 1992;4:55-65.

Lovallo W. The cold pressor test and autonomic function: a review and integration. Psychophysiology 1975;12:268-81.

Lovallo WR, Wilson MF, Pincomb GA, Edwards GL, Tompkins P, Brackett DJ. Activation patterns to aversive stimulation in man: passive exposure versus effort to control. Psychophysiology 1985;22:283-91. 
Mitchell LA, MacDonald RAR, Brodie EE. Temperature and the cold pressor test. J Pain 2004;5:233-7.

Peckerman A, Saab PG, McCabe PM, Skyler JS, Winers RW, Llabre MM, et al. Blood pressure reactivity and perception of pain during the forehead cold pressor test. Psychophysiology 1991;28:485-95.

Pertovaara A, Kemppainen P, Vuolteenaho O, Leppäluoto J. The effect of tourniquetinduced ischemic pain and electrotactile thresholds, blood pressure and $\beta$-endorphin level in plasma. In: Bromm B, editor. Pain measurement in man. Neurophysiological correlates of pain. Amsterdam: Elsevier; 1984. p. 475-81.

Posner J, Telekes A, Crowley D, Phillipson R, Peck AW. Effects of an opiate on coldinduced pain and the CNS in healthy volunteers. Pain 1985;23:73-82.

Randich A, Maixner W. Interactions between cardiovascular and pain regulatory systems. Neurosci Biobehav Rev 1984;8:343-67.

Ring C, Edwards L, Kavussanu M. Effects of isometric exercise on pain are mediated by blood pressure. Biol Psychol 2008;78:123-8.
Smith GM, Egbert LD, Markowitz RA, Mosteller F, Beecher HK. An experimental pain method sensitive to morphine in man: the submaximal effort tourniquet technique. J Pharmacol Exp Ther 1966;154:468-74.

Steptoe A, Melville D, Ross A. Behavioral response demands, cardiovascular reactivity, and essential hypertension. Psychosom Med 1984;46:33-48.

Tousignant-Laflamme Y, Rainville P, Marchand P. Establishing a link between heart rate and pain in healthy subjects: a gender effect. J Pain 2005;6:341-7.

Villanueva L, Bouhassira D, Le Bars D. The medullary subnucleus reticularis dorsalis (SRD) as a key link in both the transmission and modulation of pain signals. Pain 1996;67:231-40.

Weise F, Laude D, Girard A, Zitoun P, Siché J-P, Elghozi J-L. Effects of the cold pressor test on short-term fluctuations of finger arterial blood pressure and heart rate in normal subjects. Clin Auton Res 1993;3:303-10.

Wolf S, Hardy JD. Studies on pain. Observations on pain due to local cooling and on factors involved in the "cold pressor" effect. J Clin Invest 1941;20:521-33. 